Case Report

\title{
An Atypical HNF4A Mutation Which Does Not Conform to the Classic Presentation of HNF4A-MODY
}

\author{
Andrew J. Spiro $\mathbb{D},{ }^{1}$ Katherine N. Vu, ${ }^{2,3}$ and Alicia Lynn Warnock $\mathbb{D}^{2,3}$ \\ ${ }^{1}$ Department of Internal Medicine, Walter Reed National Military Medical Center, Bethesda, MD, USA \\ ${ }^{2}$ Department of Endocrinology, Metabolism and Diabetes, Walter Reed National Military Medical Center, Bethesda, MD, USA \\ ${ }^{3}$ Uniformed Services University of Health Sciences, Bethesda, MD, USA
}

Correspondence should be addressed to Andrew J. Spiro; andrewspiro22@gmail.com

Received 16 January 2018; Revised 23 March 2018; Accepted 26 April 2018; Published 28 May 2018

Academic Editor: Michael P. Kane

Copyright (C) 2018 Andrew J. Spiro et al. This is an open access article distributed under the Creative Commons Attribution License, which permits unrestricted use, distribution, and reproduction in any medium, provided the original work is properly cited.

\begin{abstract}
Objective. To present the case of an atypical Hepatocyte Nuclear Factor 4 Alpha (HNF4A) mutation that is not consistent with the classically published presentation of HNF4A-Mature Onset Diabetes of the Young (MODY). Methods. Clinical presentation and literature review. Results. A 43-year-old nonobese man was referred to the endocrinology clinic for evaluation of elevated fasting blood glucose (FBG) measurements. Laboratory review revealed prediabetes and hypertriglyceridemia for the previous decade. Testing of autoantibodies for type 1 diabetes was negative. Genetic testing showed an autosomal dominant, heterozygous missense mutation (c.991C>T; p.Arg331Cys) in the HNF4A gene, which is correlated with HNF4A-MODY. Phenotypically, patients with an HNF4A-MODY tend to have early-onset diabetes, microvascular complications, low triglyceride levels, increased birth weight, fetal macrosomia, and less commonly neonatal hyperinsulinemic hypoglycemia. The patient did not demonstrate any of these features but instead presented with late-onset diabetes, an elevated triglyceride level, and a normal birth weight. Conclusion. Our patient likely represents an atypical variant of $H N F 4 A$-MODY with a milder clinical presentation. Patients with atypical, less-severe presentations of HNF4A-MODY may be largely undiagnosed or misdiagnosed, but identification is important due to implications for treatment, pregnancy, and screening of family members.
\end{abstract}

\section{Introduction}

MODY describes a cluster of monogenic disorders that are inherited in an autosomal dominant manner. The classic depiction of MODY is diabetes that presents before the age of 25 years, is not insulin-dependent, and shows no evidence of autoimmune pathology or insulin resistance. While MODY is only responsible for $1 \%$ of all cases of diabetes, it is the cause for $5 \%$ of people diagnosed before 45 years [1]. To date, several MODY-causing genes have been identified but the most common are glucokinase (GCK), HNF1A, and HNF4A [1]. The HNF4A-MODY (MODY 1) and HNF1A-MODY (MODY 3) phenotypes resemble one another, producing significant pancreatic $\beta$-cell dysfunction which results in hyperglycemia and microvascular complications, whereas GCK-MODY (MODY 2) produces a mild hyperglycemia, which often does not require treatment [1] (see Table 1). A recent large-scale study in the United Kingdom showed that
HNF4A-MODY (MODY 1), GCK-MODY (MODY 2), and HNF1A-MODY (MODY 3) represent $10 \%, 32 \%$, and $52 \%$ of MODY cases in that population [2]. The prevalence of different MODY mutations varies from one country to another. In countries like France, Italy, and Spain, where asymptomatic glucose testing is common, GCK-MODY (MODY 2) is the most common subtype. HNF1A-MODY (MODY 3) is the most common subtype in countries where random glucose testing is less routine [3]. We describe a patient with a heterozygous missense mutation in HNF4A whose clinical presentation does not conform to the classically described features of the HNF4A-MODY.

\section{Case Report}

A 43-year-old nonobese man was referred to the endocrinology clinic for evaluation of elevated FBG measurements. His FBG and hemoglobin A1C (HbA1C) had been in the 
TABLE 1: Comparison of patient phenotype with the common MODY subtypes.

\begin{tabular}{|c|c|c|c|c|}
\hline & Patient (HNF4A mutation) & HNF4A-MODY (MODY 1) & HNF1A-MODY (MODY 3) & GCK-MODY (MODY 2) \\
\hline Frequency $^{*}$ & - & $\leq 10 \%$ & $\sim 30-50 \%$ & $\sim 30-50 \%$ \\
\hline $\begin{array}{l}\text { Age of } \\
\text { Diagnosis }\end{array}$ & $41 \mathrm{y} / \mathrm{o}$ & $<25 \mathrm{y} / \mathrm{o}$ & $<25 \mathrm{y} / \mathrm{o}$ & $\begin{array}{c}\text { Usually age when blood } \\
\text { glucose levels first } \\
\text { measured }\end{array}$ \\
\hline Pathophysiology & - & $\begin{array}{c}\text { Transcription factor, } \\
\text { decreased insulin secretion }\end{array}$ & $\begin{array}{c}\text { Transcription factor, } \\
\text { Decreased insulin secretion }\end{array}$ & $\begin{array}{l}\text { Decreased glucose } \\
\text { sensitivity, decreased } \\
\text { glycogen storage }\end{array}$ \\
\hline Characteristics & $\begin{array}{l}\text { No current evidence of } \\
\text { microvascular complications } \\
\text { Managed with lifestyle } \\
\text { modifications } \\
\text { Hypertriglyceridemia, mildly } \\
\text { elevated LDL and VLDL } \\
\text { Normal Apo-B, Apo-A1 }\end{array}$ & $\begin{array}{c}\text { Microvascular } \\
\text { complications } \\
\text { Sensitive to sulfonylureas } \\
\text { Low TG, high LDL, low } \\
\text { HDL } \\
\text { Low Apo A-II, C-III, B } \\
\text { Fetal Macrosomia } \\
\text { Neonatal hypoglycemia }\end{array}$ & $\begin{array}{c}\text { Microvascular } \\
\text { complications } \\
\text { Sensitive to sulfonylureas } \\
\text { Normal or high HDL } \\
\text { Glycosuria }\end{array}$ & $\begin{array}{l}\text { No microvascular } \\
\text { complications } \\
\text { Mild, generally does not } \\
\text { require treatment }\end{array}$ \\
\hline
\end{tabular}

TABLE 2: Patient laboratory data over time.

\begin{tabular}{|c|c|c|c|c|c|c|c|c|}
\hline Age (years) & 36.96 & 37.01 & 41.24 & 41.43 & 43.20 & 43.27 & 43.29 & 43.35 \\
\hline $\operatorname{HbAlC}(\%)$ & & 5.7 & 6.7 & 6.3 & & 6.2 & & \\
\hline $\mathrm{FBG}(\mathrm{mg} / \mathrm{dL})$ & 123 & 113 & & & 131 & 198 & 115 & 188 \\
\hline C-peptide (ng/mL) & & & & & & & & 7.0 \\
\hline Fasting Insulin (mcU/mL) & & & & & & & 14.7 & \\
\hline Glucose, 2 hr Post $75 \mathrm{gm}$ Oral Glucose Load & & & & & & & 178 & \\
\hline Total Cholesterol (mg/dL) & 213 & 250 & 215 & 154 & 153 & & & \\
\hline HDL & 52 & 47 & 37 & 39 & 38 & & & \\
\hline TG & 277 & 342 & 397 & 165 & 144 & & & \\
\hline LDL & 106 & 142 & 107 & 81 & 88 & & & \\
\hline BMI $\left(\mathrm{kg} / \mathrm{m}^{2}\right)$ & & 25.1 & 25.6 & 24.4 & & 24.8 & & \\
\hline
\end{tabular}

HbA1C = hemoglobin A1C; FBG = fasting blood glucose; HDL = high density lipoprotein cholesterol; TG = triglyceride; LDL = low density lipoprotein cholesterol; BMI = body mass index; normal reference ranges for laboratory: (1) insulin (mcU/mL): (2.6-24.9); (2) C-peptide (ng/mL): (1.1-4.4). Note. For the duration listed, the patient was taking a moderate-intensity statin and not taking any medication for treatment of diabetes.

prediabetic range for the past decade, except for one elevated $\mathrm{HbAlC}$ of $6.7 \%$ (50 $\mathrm{mmol} / \mathrm{mol}$ ) two years prior (see Table 2). The patient denied any classic symptoms of diabetes. His medical history was notable for gout, hyperlipidemia, and hypertriglyceridemia. The patient was taking allopurinol and had been taking a moderate-intensity-statin for the previous 10 years. His mother had premature coronary artery disease (CAD) and type 2 diabetes (T2DM), controlled with oral medication. Physical exam showed a healthy, lean, and muscularly fit individual with a body mass index of $24.8 \mathrm{~kg} / \mathrm{m}^{2}$. His latest $\mathrm{HbAlC}$ was $6.2 \%(44 \mathrm{mmol} / \mathrm{mol})$ and recent $\mathrm{FBG}$ measurements were 131, 198, 115, and $188 \mathrm{mg} / \mathrm{dL}$. An oral glucose tolerance test showed a result in the prediabetic range $(178 \mathrm{mg} / \mathrm{dL})$. Autoantibodies (Glutamate Decarboxylase 65 $\mathrm{Ab}$, Pancreatic Islet Cell Ab, Islet Cells Ab 512, and Insulin $\mathrm{Ab})$ were negative. His fasting insulin level was within normal limits while a C-peptide level was mildly elevated; however, these levels were checked at different time points and do not directly correlate with one another (see Table 2). Initially, his presentation was attributed to early well-controlled T2DM with elements of metabolic syndrome; however, due to his atypical physical appearance, he was referred for genetic testing for MODY. Testing revealed an autosomal dominant, heterozygous missense mutation (c.991C > T; p.Arg331Cys) in the HNF4A gene.

\section{Discussion}

As noted above, HNF4A-MODY (MODY 1) and HNF1AMODY (MODY 3) are generally associated with the classic MODY features while GCK-MODY (MODY 2) has been recognized as a milder variant. The clinical manifestation of our patient's HNF4A mutation was atypical for multiple reasons. The primary atypical feature was that he did not meet laboratory criteria for diabetes diagnosis until the age of $41(\mathrm{HbAlC}=6.7 \% ; 50 \mathrm{mmol} / \mathrm{mol})$, after which he was able to maintain his $\mathrm{HbA1C}$ levels in the prediabetic range with only lifestyle modification. Recent data showed that $71 \%$ 
of individuals with pathogenic HNF4A mutations developed diabetes by age of 30 , with mean age of diagnosis in the early 20s. This data did not include the p.R114W mutation [4]. While uncommon, presentations later in life are not exceedingly rare. Another recent study reported approximately $82 \%$ penetrance of mutations at age of 40 years [5]. Aside from early-onset diabetes, HNF4A mutations have been associated with increased birth weight and macrosomia [6]. In one study, $56 \%$ of mutation carriers met criteria for macrosomia and carriers demonstrated a $790 \mathrm{~g}$ average increase in birth weight compared to noncarrier family members [7]. Our patient reported a birth weight between 6 and $7 \mathrm{lbs}$ and had no history of macrosomia. Examination of the lipid profiles in HNF4A-MODY has revealed decreased serum triglycerides and Apo AII [6]. Evidence has also shown high LDL, low HDL, low apo CIII, and low apo B [1]. In contrast, our patient demonstrated consistent hypertriglyceridemia and normalto-high levels of HDL and LDL. Apo B and Apo A-I were within the normal range.

The variance between our patient's clinical presentation and that of classic HNF4A-MODY can be explored by examining the function of the HNF4A protein. HNF4A is a transcription factor that is primarily expressed in the liver, in addition to the kidneys and pancreas [8]. It is not completely understood how HNF4A mutations result in impaired $\beta$-cell function and insulin secretion or alter the lipid profile. It is known though that HNF4A regulates expression of genes involved in glucose transport (GLUT2), glycolysis (aldolase B, liver pyruvate kinase), and lipid metabolism (Apo AII, apoB, and apoCIII) [8]. It has been proposed that low triglyceride concentrations found in typical HNF4A-MODY could result from the decreased transcriptional activity of the mutated HNF4A leading to less expression of apoB and apoCIII [8]. In our patient, the delayed and less-severe presentation of diabetes supports a milder impairment of $\beta$-cell function and insulin secretion in the pancreas. His elevated triglyceride level supports that expression of apoCIII and apoB has not been altered in the liver in the typical manner. It must be considered though that a definitive conclusion cannot be drawn based on a single patient. Other predisposing or protective factors should be weighed. Our patient's elevated triglyceride levels may not be related to his HNF4A mutation but instead due to a distinct and separate condition. With consideration of his mother's reported history of CAD and T2DM, he may have a separate predisposition to hypertriglyceridemia or metabolic syndrome.

There are more than 103 HNF4A-MODY mutations in 173 families and there is great variation in the types of mutations (i.e., missense, frameshift, and nonsense) [6]. Thus, there is potential for a spectrum of phenotypes. Our patient likely represents a variant of $H N F 4 A$-MODY with a milder clinical presentation than the classic picture. A recent study which described the (p.R114W) mutation presented an HNF4AMODY variant with a less-severe presentation of diabetes, noting a pathogenic penetrance of only $54 \%$ by age of 30 [4]. Patients with less-severe HNF4A-MODY variants, like those with the (p.R114W) mutation, present a particularly difficult population to diagnose and they may in fact be largely misdiagnosed. In the United Kingdom, it is estimated that $>80 \%$ of MODY is misdiagnosed [2]. The milder degree of $\beta$ cell impairment and the delayed age of diagnosis can strongly mimic T2DM; however, clinical suspicion for MODY should increase in diabetics with negative autoimmune markers who do not demonstrate obesity and the metabolic syndrome [1]. Distinguishing HNF4A-MODY from T2DM has important implications for management. Sensitivity to sulfonylureas is well-established in HNF4A-MODY [6]. Use of sulfonylureas in HNF4A-MODY and HNF1A-MODY has been shown to improve glycemic control and can improve a patient's quality of life by avoiding insulin therapy [1]. Further, HNF4A mutations can have important ramifications during pregnancy. If either the mother or the father is known to be a mutation carrier, then there is increased risk of complications due to macrosomia, while the neonates who inherit the mutation are at risk of neonatal hypoglycemia [6]. Lastly, identifying an HNF4A mutation allows family members to be screened for carrier status and receive appropriate counselling. Genetic screening is recommended for all diabetic family members and genetic counselling is recommended for all nondiabetic members [1].

\section{Conclusion}

Our patient exhibited an atypical clinical presentation of an HNF4A mutation which likely represents a less-severe variant of HNF4A-MODY. Features of this milder variant include late-onset diabetes, hypertriglyceridemia, and a normal birth weight. There is great variation in the types of HNF4A mutations and potential for a spectrum of resultant phenotypes. Diagnosis of individuals who present with atypical, lesssevere presentations of $H N F 4 A-M O D Y$ is difficult, and they may be largely misdiagnosed. Identification of these patients is important due to implications for treatment, pregnancy, and the screening of family members.

\section{Data Availability}

The patients laboratory results are recorded and available in the military health care record system.

\section{Disclosure}

The views expressed in this manuscript are those of the authors and do not reflect the official policy of the Department of the Navy, the Department of Defense or the United States Government. One or more of the authors are military service members (or employee of the U.S. Government). This work was prepared as part of the authors' official duties. Title 17 U.S.C. 105 provides the "Copyright protection under this title is not available for any work of the United States Government." Title 17 U.S.C. 101 defines a U.S. Government work as a work prepared by a military service member or employee of the U.S. Government as part of that person's official duties. The authors certify that all individuals who qualify as authors have been listed; each has participated in the conception and design of this work, the analysis of data (when applicable), the writing of the document, and/or the 
approval of the submission of this version; the document represents valid work; if we used information derived from another source, we obtained all necessary approvals to use it and made appropriate acknowledgements in the document; and each takes public responsibility for it.

\section{Conflicts of Interest}

The authors have no multiplicity of interest to disclose.

\section{References}

[1] A. Anik, G. Çatli, A. Abaci, and E. Böber, "Maturity-onset diabetes of the young (MODY): an update," Journal of Pediatric Endocrinology and Metabolism, vol. 28, no. 3-4, pp. 251-263, 2015.

[2] B. M. Shields, S. Hicks, M. H. Shepherd, K. Colclough, A. T. Hattersley, and S. Ellard, "Maturity-onset diabetes of the young (MODY): how many cases are we missing?" Diabetologia, vol. 53, no. 12, pp. 2504-2508, 2010.

[3] G. Thanabalasingham and K. R. Owen, "Diagnosis and management of maturity onset diabetes of the young (MODY)," BMJ, vol. 343, no. 7828, Article ID d6044, 2011.

[4] T. W. Laver, K. Colclough, M. Shepherd et al., "The common p.R114W HNF4A mutation causes a distinct clinical subtype of monogenic diabetes," Diabetes, vol. 65, no. 10, pp. 3212-3217, 2016.

[5] K. A. Patel, J. Kettunen, M. Laakso et al., "Heterozygous RFX6 protein truncating variants are associated with MODY with reduced penetrance," Nature Communications, vol. 8, no. 1, p. 888, 2017.

[6] K. Colclough, C. Bellanne-Chantelot, C. Saint-Martin, S. E. Flanagan, and S. Ellard, "Mutations in the genes encoding the transcription factors hepatocyte nuclear factor 1 alpha and 4 alpha in maturity-onset diabetes of the young and hyperinsulinemic hypoglycemia," Human Mutation, vol. 34, no. 5, pp. 669685, 2013.

[7] E. R. Pearson, S. F. Boj, A. M. Steele et al., "Macrosomia and Hyperinsulinaemic Hypoglycaemia in Patients with Heterozygous Mutations in the HNF4A Gene," PLoS Medicine, vol. 4, pp. 760-769, 2007.

[8] M. Lehto, P.-O. Bitzén, B. Isomaa et al., "Mutation in the HNF$4 \alpha$ gene affects insulin secretion and triglyceride metabolism," Diabetes, vol. 48, no. 2, pp. 423-425, 1999. 


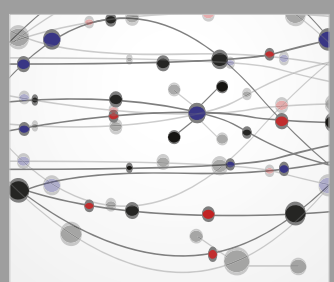

The Scientific World Journal
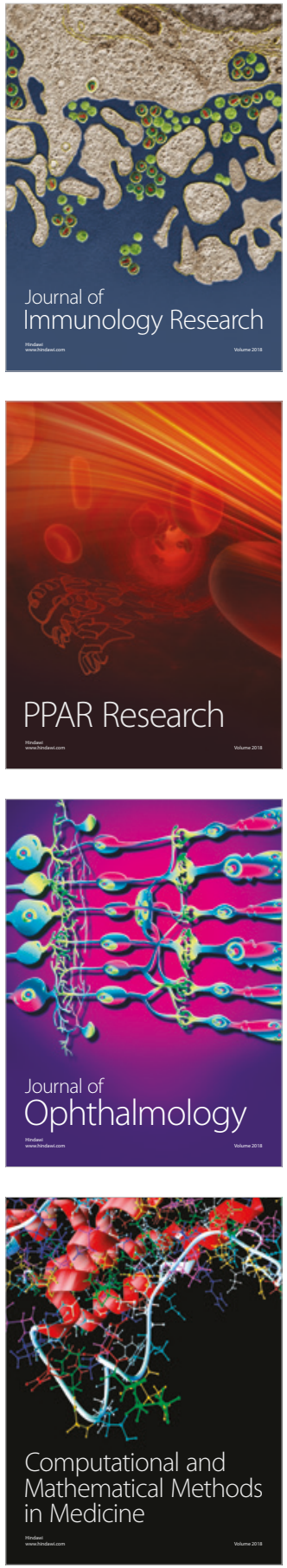

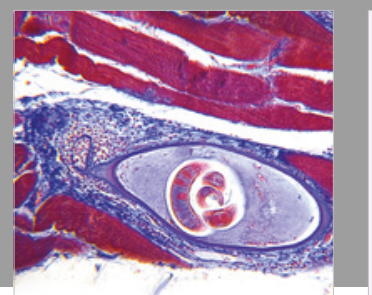

Gastroenterology Research and Practice

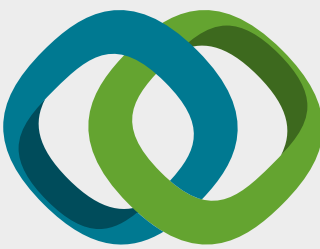

\section{Hindawi}

Submit your manuscripts at

www.hindawi.com
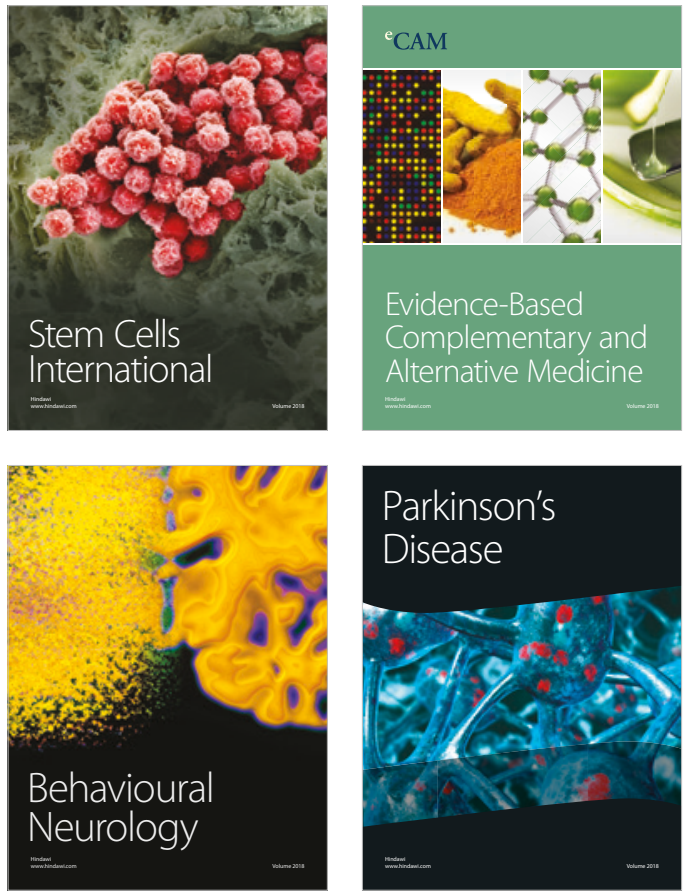

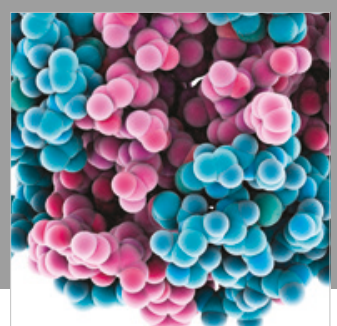

ournal of

Diabetes Research

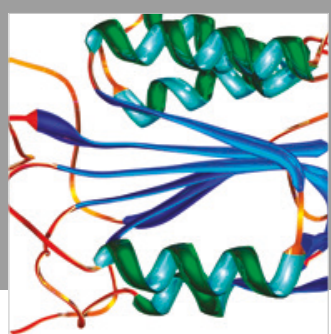

Disease Markers
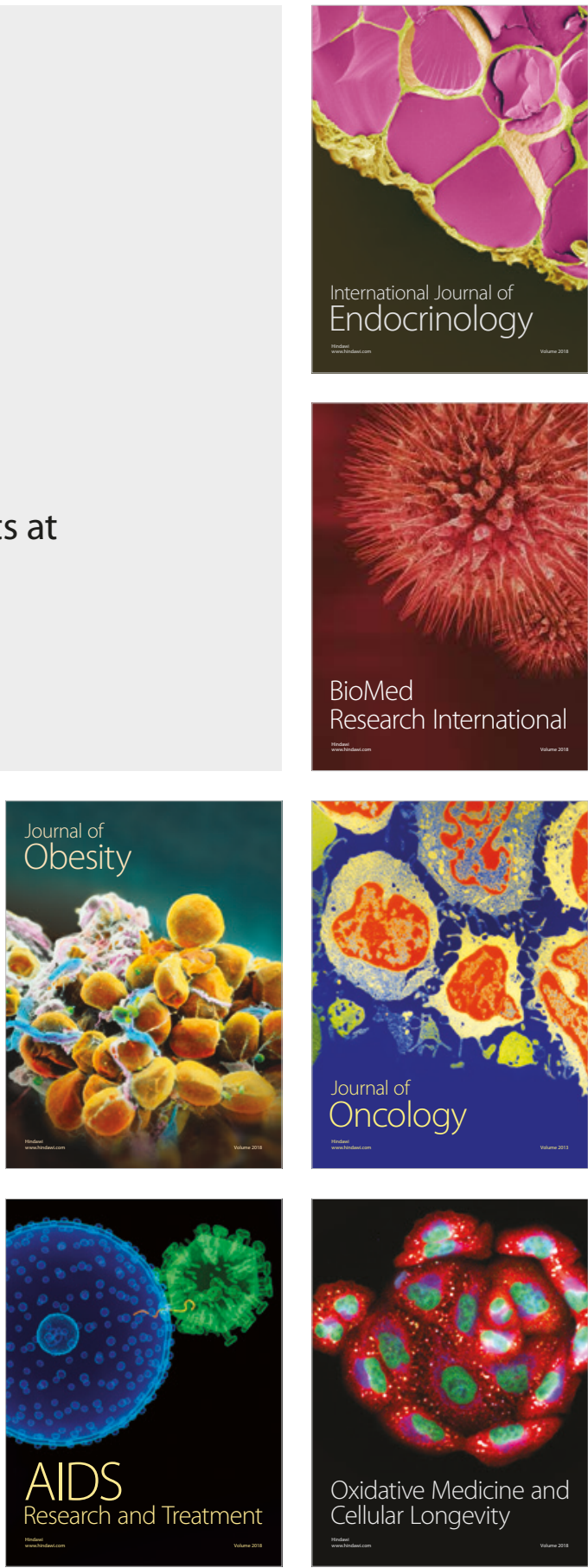